\title{
Homozygous Familial Hypercholesterolemia (HoFH) in Saudi Arabia and Two Cases of Lomitapide Use in a Real-World Setting
}

\author{
Moeber Mahzari · Hawazen Zarif
}

Received: February 17, 2021 / Accepted: March 18, 2021 / Published online: April 7, 2021

(C) The Author(s) 2021

\section{ABSTRACT}

Introduction: Homozygous familial hypercholesterolemia (HoFH) is a rare, genetic condition in which mutations in key peptides involved in the low-density lipoprotein receptor (LDL-R) pathway result in markedly elevated levels of circulating LDL-cholesterol (LDL-C). Patients are at high risk of developing earlyonset atherosclerotic cardiovascular disease

Moeber Mahzari and Hawazen Zarif are co-first authors of the manuscript.

M. Mahzari ( $\square)$

College of Medicine, King Saud Bin Abdulaziz

University for Health Sciences, Riyadh, Saudi Arabia

e-mail: moeber@hotmail.com

\section{Mahzari}

Department of Medicine, Ministry of National Guard Health Affairs, Riyadh, Saudi Arabia

\section{Mahzari}

King Abdullah International Medical Research Center, Riyadh, Saudi Arabia

H. Zarif

College of Medicine, King Saud Bin Abdulaziz University for Health Sciences, Jeddah, Saudi Arabia

H. Zarif

Department of Medicine, Ministry of National Guard Health Affairs, Jeddah, Saudi Arabia

H. Zarif

King Abdullah International Medical Research Center, Jeddah, Saudi Arabia with associated mortality risks. Treatment options are extremely limited, and aspects of society and medical care in Saudi Arabia have the potential to increase incidence and limit treatment pathways in HoFH.

Methods: Along with a brief review of the evidence available on HoFH we describe the treatment of two Saudi Arabian patients with $\mathrm{HoFH}$ diagnosed and treated in accordance with local clinical practices and with the microsomal triglyceride transferase protein inhibitor lomitapide.

Results: HoFH in Saudi Arabia is characterized by problems associated with consanguinity, a lack of access to lipoprotein apheresis, and pressures to proceed to liver transplant. Among the case histories, the first patient was commenced on lomitapide therapy, and underwent a dramatic decrease in LDL-C levels from 16.5 to $2.2 \mathrm{mmol} / \mathrm{L}$ (87\% decrease). This patient had problems with access to lomitapide and cessation of the drug resulted in rebound in LDL-C to $22 \mathrm{mmol} / \mathrm{L}$. The second patient experienced delayed commencement of lomitapide therapy. Despite a $45 \%$ decrease in LDL-C levels from 15.3 to $6.9 \mathrm{mmol} / \mathrm{L}$, the patient died the following year at age 26 years from complications subsequent to cardiovascular surgery. Lomitapide was well tolerated in both patients

Discussion: The experience of these two cases highlights the need for prompt, effective, and sustained intervention in HoFH to prevent cardiovascular morbidity and mortality. 
Lomitapide is an effective therapy for $\mathrm{HoFH}$, and we look forward to improved access to this drug in Saudi Arabia, where there is a chronic unmet medical need in HoFH.

Keywords: Atherosclerotic cardiovascular disease; Homozygous familial hypercholesterolemia; Lomitapide; Lowdensity lipoprotein cholesterol

\section{Key Summary Points}

Why carry out this study?

Homozygous familial

hypercholesterolemia (HoFH), which

results in early-onset atherosclerotic cardiovascular disease due to markedly

elevated low-density lipoprotein

cholesterol levels, presents unique

challenges in Saudi Arabia as a result of

organizational, cultural, and genetic

issues, disease severity, and prevalence

due to consanguinity and economic

circumstances.

Understanding of these factors is critical to the early detection and effective treatment of HoFH.

\section{What was learned from the study?}

We have reviewed the literature on HoFH relevant to Saudi Arabia and the Gulf region

We have also presented two case studies from Saudi Arabia that underscore some of the particular challenges faced by patients and their medical teams.

One case highlighted the dangers posed by drug access issues, and the other case resulted in early death associated with late and mismanaged specialist referral.

\section{DIGITAL FEATURES}

This article is published with digital features, including a summary slide, to facilitate understanding of the article. To view digital features for this article go to https://doi.org/10.6084/ m9.figshare. 14224313

\section{INTRODUCTION}

Homozygous familial hypercholesterolemia (HoFH) is a life-threatening genetic disorder associated with very high levels of low-density lipoprotein cholesterol (LDL-C)—often 10 times normal levels-leading to severe and progressive atherosclerotic disease. This results in premature, life-threatening cardiac events, which may occur in the first decade of life if the condition is undiagnosed and untreated. If untreated, the average age of death is 18 years, although deaths before the age of 5 years have been reported in the literature $[1,2]$.

The nature of the underlying genetic mutations results in a spectrum of clinical presentations, with mutations of the LDL receptor gene resulting in virtually no receptor functionality (receptor null or negative), which is associated with more severe disease phenotypes [1].

The overall global prevalence of HoFH has been estimated at approximately 1:300,000 people [3]. This is considerably higher than historical estimates from the 1970s of around one case per million population [4].

Information on the prevalence of HoFH in Saudi Arabia has been scarce. This review and case series examines the state-of-the-art of HoFH in Saudi Arabia and the Gulf region, and provides two illustrative cases that highlight some of the practical and organizational challenges faced in the treatment of HoFH in Saudi Arabia. The surviving patient provided consent for publication. For the patient who died, consent was provided by their next of kin. 


\section{HOFH IN SAUDI ARABIA AND THE GULF REGION}

In Saudi Arabia, estimates of the prevalence of hypercholesterolemia and dyslipidemia vary. A 2008 report of data from the Saudi population aged 30-70 years found evidence of hypercholesterolemia in $54 \%$ of persons with outpatient laboratory data [5]. A Ministry of Health survey in 2013 produced a prevalence estimate of dyslipidemia of $8.5 \%$ in the general Saudi population [6]. The Africa Middle East Cardiovascular Epidemiological study, which also uses stable outpatient data, indicated that the overall Middle East and African prevalence of dyslipidemia was as high as $70 \%[7,8]$. Looking at familial hypercholesterolemia (FH) in particular, a study was conducted in 2018 of 3224 patients hospitalized with acute coronary syndrome (ACS) in which the Dutch Lipid Clinic Network criteria were applied to determine the prevalence of $\mathrm{FH}$ [9]. Among these patients, $3.7 \%$ were considered to have $\mathrm{FH}$. These data are not specific to HoFH and are based on a preselected cohort of patients with ACS [9]; however, interestingly, they represent twice the prevalence of a similar group of ACS patients studied in Switzerland [10].

In 2020, initial data from the Gulf FH registry estimated that the prevalence of definite and probable FH cases combined is $1: 232$, which is close to estimates for Western populations [11]. However, again, these data are not specific to HoFH. Additionally, the registry data are overdue for a forthcoming update, and indications from our own observations suggest that the published data on FH in Saudi Arabia substantially underestimate the true prevalence.

When a Gulf region guidelines committee convened to set standards of care for patients with $\mathrm{HoFH}$, the group acknowledged that there are insufficient data from the area to estimate the prevalence of HoFH with the same degree of certainty as has been possible for the Netherlands [12]. A rough calculation by the committee, using available data from Oman, suggested that the prevalence is higher than one per million, but it was not possible to make a more accurate assessment at that time [12]. Similarly, if we take the 1:232 published prevalence of $\mathrm{FH}$ [11], and apply Hardy-Weinberg principles, then the possible prevalence of HoFH comes out as 4.6 per million. Calls for a registry have been made in an effort to fully understand $\mathrm{HoFH}$ prevalence in the Gulf [13].

Despite the lack of reliable data, the prevalence of HoFH in the Gulf region is likely to be higher than that of the global population. There are two principal factors that support this notion.

Firstly, there is a higher rate of consanguineous marriage in the Gulf region compared with the rest of the world. Consanguinity increases the chances of two parents with rare disease alleles producing offspring with pathological genetic conditions [14]. Consanguinity in the Gulf region has been a concern for excess transmission of HoFH [12]. Regardless of the relative prevalence of $\mathrm{HoFH}$, logic suggests that consanguinity could increase the prevalence of HoFH should two aberrant alleles combine in a family. In 1995, a survey of 3212 Saudi families found consanguinity in $57.7 \%$ of couples, $28.4 \%$ of which were first-cousin marriages [15]. More recently, in 2014, a survey of 600 Saudi women revealed no decline in consanguinity across two generations. Among the women surveyed, first-cousin marriages were present in $30 \%$ of directly surveyed cases, and in $23 \%$ of the parent population [16]. These data show that consanguinity is highly prevalent in Saudi Arabia, and that there is no evidence that the practice is in danger of dying out. Secondly, there is a founder effect in Saudi Arabia that is probably amplified by consanguinity. Saudi Arabia is home to a characteristic mutation exon 14 of the $L D L R$ that has arisen in approximately $40 \%$ of the Saudi Arabian FH population [17]. The mutation is a frameshift aberration resulting in c.2027delG, p.(G676Afs*33), and appears to originate in a series of tribes living in the northern and western areas of Saudi Arabia [17]. Homozygotes with this mutation have a severe form of HoFH. Functional studies have confirmed that frameshift occurs in the critical EGFP homologous domain of the LDL-R and that folding of the LDL-R peptide is entirely disrupted by the mutation [17]. 


\section{DISEASE DIAGNOSIS AND AWARENESS}

Diagnosis of $\mathrm{HoFH}$ is made on the basis of clinical characteristics and/or genetic confirmation. In the absence of a confirmatory genetic test, the clinical criteria that indicate HoFH are an untreated LDL-C level higher than $13 \mathrm{mmol} / \mathrm{L}(500 \mathrm{mg} / \mathrm{dL})$ or treated LDL-C level of at least $8 \mathrm{mmol} / \mathrm{L}(300 \mathrm{mg} / \mathrm{dL})$, together with either cutaneous or tendon xanthoma before age 10 years, or untreated elevated LDL-C levels consistent with heterozygous $\mathrm{FH}$ in both parents [1]. A genetic test can be used to confirm the diagnosis; equally, identification of two mutant alleles at the $L D L R, A P O B, P C S K 9$, or LDLRAP1 gene loci can be definitive for $\mathrm{HoFH}$ regardless of clinical criteria [1]. In Saudi Arabia, a systematic review collected all FH-related mutations reported in the population, resulting in 21 variants mapped to three genes, $L D L R$, $A P O B$, and PCSK9. Most (more than 80\%) of these variants were in $L D L R$. Two of these were found to be novel $L D L R$ variants, c.1332dup (p.D445*) [18] and c.2026delG (p.G676Afs*33) [19]. Variations in PCSK9 are the second most common in Saudi Arabia, and variation in $A P O B$ among the least common [20].

Once a HoFH proband has been identified, physicians in many countries encourage cascade screening of the immediate family to identify any further at-risk patients [21]. In this schema, first-, second-, and third-degree relatives, whether affected or not, usually undergo thorough genetic testing as they would logically have respective $50 \%, 25 \%$, and $12.5 \%$ possibilities of inheriting the mutation in the absence of consanguinity [20]. With consanguinity, the risks of inheriting the mutation may be higher. In Saudi Arabia, calls have been made to increase cascade screening since 2009 [22, 23]. The Dutch StOEH (Stichting Opsporing Erfelijke Hypercholesterolemie) has conducted a successful cascade screening program since 1994, resulting in 18,000 diagnoses up to 2009, with associated improvements in survival [23]. This program has been offered as a model for $\mathrm{HoFH}$ screening in Saudi Arabia [23]; however, no screening system currently exists in the country.

Accurate diagnosis of HoFH in Saudi Arabia is hindered by a general lack of disease awareness among physicians. A 2017 survey of 294 physicians at four tertiary hospitals in Riyadh found that $92.9 \%$ of respondents had poor knowledge of $\mathrm{FH}$ (below a score of 4 on a 7-point scale) [24]. A second survey in Riyadh in 2015 surveyed 115 family physicians and found poor levels of $\mathrm{FH}$-related knowledge in $48.4 \%$ of respondents, despite $72.4 \%$ of the same sample professing to have a good understanding of the condition [25]. Some improvements in awareness of FH were evident in a 2020 survey conducted among 170 medical interns in Jeddah. FH was defined correctly by $76.5 \%$ of respondents, and the lipid profile was correctly described by $52.4 \%$; however, knowledge of inheritance patterns and coronary artery disease (CAD) risk in $\mathrm{FH}$ remained low $(12.4 \%$ and $7.1 \%$, respectively) [26]. While awareness of $\mathrm{FH}$ appears to be gradually improving in Saudi Arabia, this may not be surprising given that $\mathrm{FH}$ is the most common autosomal dominant condition in man, affecting 1:200 people [27]. $\mathrm{HoFH}$, on the other hand, is far more rare and has a more complicated inheritance pattern than FH. Therefore, there is likely to be a long way to go before physicians in Saudi Arabia are routinely aware of the diagnosis, risks, inheritance, and treatment of FH's more dangerous cousin.

\section{TREATMENT OF HOFH IN SAUDI ARABIA}

There is no cure for $\mathrm{HoFH}$, and treatment protocols are geared towards reducing LDL-C levels such that cumulative, life-long exposure to LDL-C levels is brought into a region where the patient's life may be extended beyond the 20-30-year limit probable for most untreated patients [1].

Targets for LDL-C levels in HoFH have been set by the European Atherosclerosis Society (EAS). In 2014 guidelines specific to $\mathrm{HoFH}$, Cuchel et al. suggested a target LDL-C of lower than $1.8 \mathrm{mmol} / \mathrm{L}(70 \mathrm{mg} / \mathrm{dL}$ in adults with 
atherosclerotic cardiovascular disease, ASCVD), and lower than $3.5 \mathrm{mmol} / \mathrm{L}(135 \mathrm{mg} / \mathrm{dL})$ in children [1]. In 2019 general guidance for patients with $\mathrm{FH}$ at risk of $\mathrm{CV}$ events was revised to set targets at lower than $1.4 \mathrm{mmol} / \mathrm{L}(55 \mathrm{mg} /$ dL) [28]. These stringent targets require prompt and effective treatment to avoid the clinical consequences of elevated LDL-C levels.

In contrast to $\mathrm{FH}$, patients with $\mathrm{HoFH}$ have a limited response to statins [29-32], possibly due to reduced LDL-R functionality. Therefore, alternative strategies need to be explored. Until quite recently, with the lack of additional pharmacotherapies, only two options existedliver transplant and lipoprotein apheresis (LA) [1].

The premise of liver transplant is that dysfunctional host LDL-R is replaced with functioning donor LDL-R, thereby enabling clearance of cholesterol from the blood. Liver transplant is a risky enterprise that essentially replaces the disease of HoFH with a secondary disease of graft versus host disease (GVHD), which also requires life-long therapy [1]. From a practical standpoint, suitable liver donors are rare, and therefore liver transplant cannot be relied on as any sort of mainstay of $\mathrm{HoFH}$ therapy. Additionally, in the Gulf region, there is enormous demand for liver transplant; however, the indications are mainly for advanced liver failure due to different causes of hepatitis [33]. There are no data on liver transplant for HoFH in Saudi Arabia, but it is not a widespread practice due to the limitations discussed here.

LA can be a successful procedure, but it needs to be applied weekly or biweekly to remain effective in the majority of cases [34]. If LA is not used optimally, then cyclical rebound of LDL-C levels between procedures can continue to expose the patient to high cumulative levels of LDL-C [34]. Weekly/biweekly LA places patients and carers under a tremendous burden that disrupts work and schooling [35]. Additionally, there are many countries where LA is unavailable [35]. In Saudi Arabia, there were three centers that offered LA, but all of them were in Riyadh. As of 2017, only one of these centers remained active, in which more than 80 patients with molecularly confirmed HoFH were undergoing treatment [20]. This leaves many patients across the two million square kilometers of Saudi Arabia essentially unable to access LA. Additionally, in Saudi Arabia, there is a cultural issue whereby patients and families may refuse LA on the basis of the stigma associated with a chronic illness-this is particularly problematic for young, single, female patients. No patient advocacy groups exist to promote LA or to place pressure on healthcare systems to provide it.

The obvious challenges of HoFH treatment and the large unmet medical need for in the condition have led to the development of additional pharmacotherapies that work to reduce circulating levels of LDL-C. At present, there are two types of therapy available for patients with HoFH. The first of these is PCSK9 inhibitors. PCSK9 mediates degradation of LDL$\mathrm{R}$ and thereby promotes clearance of LDL-C from the blood [36]. Loss-of-function mutations in PCSK9 are protective for coronary heart disease (CHD) [36]. Therefore, inhibition of PCSK9 has been explored as a therapeutic option for FH, including HoFH [37-40]. However, while PCSK9 inhibition has shown positive results for patients with heterozygous $\mathrm{FH}[37,39]$, for patients with $\mathrm{HoFH}$ and two alleles for nonfunctioning LDL-R, PCSK9 inhibition simply promotes the persistence of low-activity LDL-R [41]. This means that PCSK9 inhibitors have limited value in HoFH. This is borne out by the TAUSSIG study of evolocumab in patients with $\mathrm{FH}$, which found that mean LDL-C was reduced by $25 \%$ with evolocumab, but there was no effect in patients with null mutations (LDL-R function less than $2 \%$ ) [42].

The second mode of therapy that has become available for patients with $\mathrm{HoFH}$ is the microsomal triglyceride transfer protein (MTP) inhibitor lomitapide. Lomitapide inhibits MTP, thereby reducing the production of apolipoprotein B [43]. In turn, this reduces the circulating levels of LDL-C in a manner that is independent of the LDL-R [43]. Therefore, lomitapide has the potential for efficacy in clinical situations such as HoFH where the function of the LDL-R is severely diminished.

Lomitapide has been studied in a pivotal phase 3 study with a 26-week double-blind phase, followed by an open-label extension 
$[44,45]$. In the phase 3 study, 29 patients with HoFH had lomitapide (5-60 mg/day) added to standard of care, which included LA. Mean LDL$\mathrm{C}$ levels were reduced by $50 \%$ at week 26 [45]. In the extension study, by week 246, 14 (74\%) patients achieved LDL-C lower than $2.6 \mathrm{mmol} / \mathrm{L}$ $(100 \mathrm{mg} / \mathrm{dL})$, and $11(58 \%)$ patients achieved LDL-C lower than $1.8 \mathrm{mmol} / \mathrm{L}$ (70 $\mathrm{mg} / \mathrm{dL})$ on at least one occasion during the study [44].

Adverse events (AEs) with lomitapide are centered around its mode of action whereby lipids are retained in the gastrointestinal tract. Therefore, common AEs include diarrhea, nausea, dyspepsia, and vomiting [44]. In the main, gastrointestinal adverse events associated with lomitapide are mild, transient, and can be managed if dietary restrictions are followed [46]. Patients receiving lomitapide are advised to eat a diet in which less than $20 \%$ of energy is derived from fat [47].

Lomitapide is approved as an adjunct to lipid-lowering treatment, with or without apheresis, in adult patients with HoFH $[47,48]$.

Data are emerging from the Lomitapide Observational Worldwide Evaluation Registry (LOWER). In March 2020, 187 patients were enrolled and mean lomitapide exposure was 47.1 months [49]. AEs thus far in LOWER have been less frequent than in the clinical trial [50]. This pattern of LDL-lowering efficacy, fewer AEs, and lower lomitapide doses than the clinical trial is echoed in a real-world case series of lomitapide in HoFH.

\section{REAL-WORLD CASES OF HOFH IN SAUDI ARABIA}

Reimbursement approval for lomitapide in Saudi Arabia was granted in December 2020. We have been fortunate to have access to lomitapide for a limited number of patients via an expanded access program and off-formulary permission. Among these patients are two individuals diagnosed with HoFH in childhood and late teens. These cases illustrate the challenges of treating HoFH in Saudi Arabia. One of the patients (patient 1) was diagnosed at age 7 years with homozygous $L D L R$ mutation and two compound heterozygous mutations in
SLCO1. The second patient (patient 2) was diagnosed at age 18 years on the basis of clinical parameters alone. No genotyping was conducted in the second patient. Both patients were treated in accordance with local protocols, which are in line with currently accepted guideline standards on the treatment of $\mathrm{HoFH}$ [1]. Lomitapide was paid for by the Saudi Ministry of National Guard Health Affairs.

\section{Patient 1}

Patient 1 is female and was diagnosed with $\mathrm{HoFH}$ at age 7 years. Genotyping identified a homozygous LDLR mutation (c.2027delG: p.Gly676Alafs*33), which is the classic, Northern Saudi Arabian founder mutation described by Al-Allaf et al. [17]. The patient also had two compound heterozygous mutations in SLCO1 (c.1738C >T: p.Arg580* and c.521T>C p.Val174Ala). There was a family history of high cholesterol. The father suffered sudden death at age 36 years; two paternal half-brothers had high cholesterol; and the mother also had elevated LDL-C levels. Genotyping was not available for the parents, and the family was not cascade screened because of their remote, rural location. Xanthomas were present on the patient's knees, ankles, and elbows since age 3 years.

At 13 years, the patient underwent percutaneous coronary intervention to the right coronary artery for confirmed CAD. At age 14 years, the patient had a double coronary artery bypass graft surgery and aortic valve replacement for moderate aortic stenosis. The patient was receiving lipid-lowering therapy in the form of rosuvastatin $40 \mathrm{mg} /$ day, ezetimibe $10 \mathrm{mg} /$ day, and evolocumab $420 \mathrm{mg}$ once monthly. At age 16 years, LDL-C levels remained high (13.3 mmol/L; Fig. 1). Lomitapide was commenced on an off-formulary basis at $5 \mathrm{mg}$ /day and gradually escalated to $40 \mathrm{mg} /$ day.

LDL-C levels reduced over the course of 1 year to $2.2 \mathrm{mmol} / \mathrm{L}$ (Fig. 1), which is below the $3.5 \mathrm{mmol} / \mathrm{L}$ target suggested for children with HoFH [1]. However, as a result of issues with drug supply, lomitapide was stopped in January 2020, and LDL-C levels immediately rebounded 


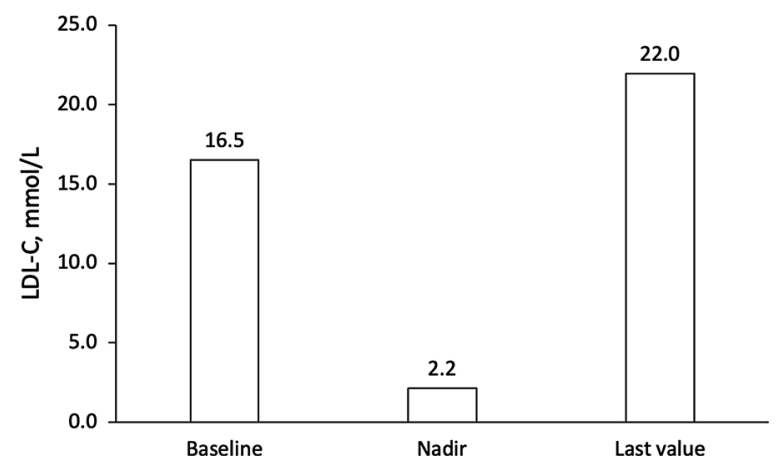

Fig. 1 LDL-C levels prior, during, and after lomitapide therapy in patient 1. LDL-C, low-density lipoprotein cholesterol; baseline is the LDL-C value taken immediately before commencement of lomitapide

to $16.5 \mathrm{mmol} / \mathrm{L}$ (Fig. 1). This demonstrates how sensitive LDL-C levels can be to lomitapide, and that once a treatment plan is in place, it is wise to continue it, where possible. It is planned to resume off-formulary lomitapide in this patient as soon as possible as the drug proved to be effective and well tolerated with no problematic AEs. In common with many young Saudi female patients with $\mathrm{HoFH}$, this individual is not interested in receiving LA, so lomitapide support is critical in this case.

\section{Patient 2}

Patient 2 was male and was diagnosed with $\mathrm{HoFH}$ at the relatively late age of 18 years. The patient was complaining of exertional shortness of breath and syncopal attacks, and was already known to have severe aortic stenosis, and there was evidence of systolic murmur radiating in the neck. The patient had xanthomas on the elbows and knees, and had corneal arcus. The patient's brother, who was diagnosed with HoFH, died age 36 years immediately after valvular heart surgery, and the mother has hypercholesterolemia. Genotyping and cascade screening were not conducted in this patient because there is no testing center in the patient's home city and therefore no mutation information is available; however, the patient met the EAS guideline criteria for clinical diagnosis of HoFH. The patient was receiving lipid- lowering therapy in the form of rosuvastatin $20 \mathrm{mg}$.

The patient was referred to a specialist lipid clinic at the age of 25 years having independently sought plastic surgery for his xanthomas that subsequently regrew. Rosuvastatin was maximized to $40 \mathrm{mg} /$ day with $10 \mathrm{mg} /$ day ezetimibe. Later, the patient was commenced on evolocumab, but there was no change in the LDL-C status, presumably because LDLR was affected by null mutations. Evolocumab was stopped, and lomitapide was commenced at $5 \mathrm{mg} /$ day with dietician referral for a low-fat diet. The dose was escalated to $10 \mathrm{mg} /$ day within 3 months. There was an immediate response to lomitapide, and LDL-C levels dropped by $45 \%$ from 15.3 to $6.9 \mathrm{mmol} / \mathrm{L}$ (Fig. 2). Lomitapide was well tolerated in this patient.

Unfortunately, it was not possible to track the progress of this patient any further. At age 26 years, the patient died 4 days after aortic root enlargement and aortic valve replacement. The exact cause of death was unknown, but was likely to be related to the patient's cholesterolassociated cardiovascular pathology. This death at an early age brings sharp focus onto one of the fundamental issues that prevents universally effective care in $\mathrm{HoFH}$ - patients are frequently diagnosed so late that ASCVD has often taken hold and the patient is on an inexorable pathway to lethal CHD. No amount of lipid lowering can save them once they reach that stage.

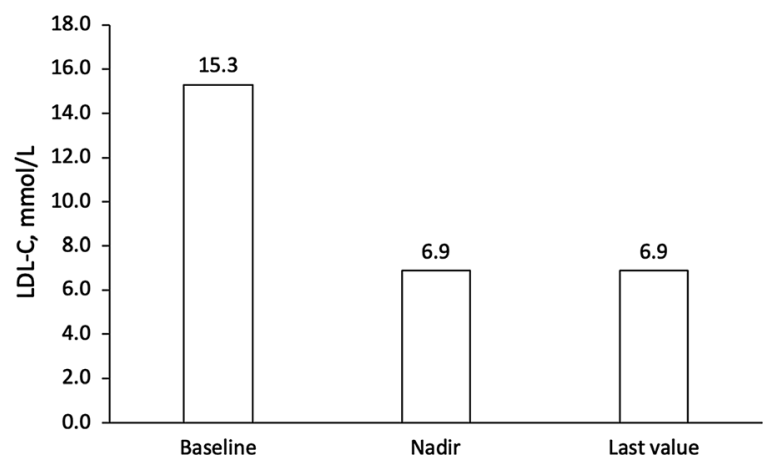

Fig. 2 LDL-C levels prior to and during lomitapide therapy in patient 2. LDL-C, low-density lipoprotein cholesterol; baseline is the LDL-C value taken immediately before commencement of lomitapide 
The lack of genotyping and onward cascade screening in the family of this patient means that there could be others living with dangerously elevated LDL-C levels who may die of sudden-onset ASCVD and/or unwittingly transmit faulty LDL-R pathway genes to offspring without the benefit of genetic counselling. In a country where consanguinity is high, information on pathogenic mutated gene transmission is critical to making informed decisions about family planning.

\section{CONCLUSIONS}

HoFH is a uniquely challenging disease that brings with it the multiple pressures of urgency to treat, access to treatment, and genetic counselling. In Saudi Arabia, and other Gulf states, these issues are amplified by cultural attitudes to illness and treatment, large geographic area, remote locations, founder mutations, and consanguinity. Despite barriers to diagnosis and care that might exist in Saudi Arabia, HoFH remains the same disease that exists elsewhere, and internationally agreed standards of care ought to be met. Certainly, access to the newly approved lomitapide has the potential to offset at least the lack of access to LA characteristic of Saudi Arabia, thereby enabling patients to achieve international guideline targets. At present, the majority of patients in Saudi Arabia and the Gulf region do not reach LDL-C targets, and there have been numerous initiatives to try to remedy the situation.

The death of patient 2, who was diagnosed at the late age of 18 years, highlights the need for early intervention with proven, effective therapies in HoFH. It also demonstrates that education is needed among physicians who may, for example, refer a patient with tendon xanthomas for dermatological assessment or plastic surgery before considering that the patient may have a deeper metabolic issue that is counting down towards early-onset ASCVD.

Urgency to diagnose and commence treatment is not the only issue that besets patients with $\mathrm{HoFH}$ in clinical care. Receiving the right treatment is also important. We have seen data that indicate that PCSK9 inhibitors do not work in patients with $\mathrm{HoFH}$ and null mutations. Therefore, if a genetic test is available and a null mutation is found (such as the classic Saudi Arabian founder mutations), then patients should be treated immediately with lomitapide as an adjunct to statins, ezetimibe, and a diet with less than $20 \%$ of energy from fat. Spending time trying a PCSK9 inhibitor simply increases the cumulative exposure to elevated levels of LDL-C. In Saudi Arabia, attitudes to LA are very negative, so it may also not be worth spending time discussing LA with recalcitrant parents or patients, and instead move straight to lomitapide.

\section{ACKNOWLEDGEMENTS}

The authors would like to thank the families of the two patients whose clinical details are given in the case presentations.

Funding. All patients were treated during the normal course of care, and were not part of a funded study. The journal's rapid service fee was funded by Amryt Pharma.

Authorship. All named authors meet the International Committee of Medical Journal Editors (ICMJE) criteria for authorship for this article, take responsibility for the integrity of the work as a whole, and have given their approval for this version to be published.

Medical Writing, Editorial, and Other Assistance. The authors wish to thank Eastmond Medicomm Ltd, which provided editorial support for this paper, funded by Amryt Pharmaceuticals DAC.

Disclosures. Dr Moeber Mahzari has no conflicts of interest to disclose. Dr Hawazen Zarif received honoraria for speaking engagements with Medtronic and Pfizer as part of an advisory board unrelated to the present work.

Authorship contributions. MM and HZ both contributed to the conception of the paper, the treatment of the patients, collection and analysis of the data, reviews of each draft stage of 
the paper and final approval of the submitted manuscript.

Compliance with Ethics Guidelines. The surviving patient provided consent for publication. For the patient who died, consent was provided by their next of kin.

Data Availability. Anonymised and redacted data from the patient cases can be made available on request to the corresponding author.

Open Access. This article is licensed under a Creative Commons Attribution-NonCommercial 4.0 International License, which permits any non-commercial use, sharing, adaptation, distribution and reproduction in any medium or format, as long as you give appropriate credit to the original author(s) and the source, provide a link to the Creative Commons licence, and indicate if changes were made. The images or other third party material in this article are included in the article's Creative Commons licence, unless indicated otherwise in a credit line to the material. If material is not included in the article's Creative Commons licence and your intended use is not permitted by statutory regulation or exceeds the permitted use, you will need to obtain permission directly from the copyright holder. To view a copy of this licence, visit http://creativecommons.org/licenses/by$\mathrm{nc} / 4.0 /$.

\section{REFERENCES}

1. Cuchel M, Bruckert E, Ginsberg $\mathrm{HN}$, et al. Homozygous familial hypercholesterolaemia: new insights and guidance for clinicians to improve detection and clinical management. A position paper from the Consensus Panel on Familial Hypercholesterolaemia of the European Atherosclerosis Society. Eur Heart J. 2014;35(32): 2146-57. https://doi.org/10.1093/eurheartj/ ehu274.

2. Nordestgaard BG, Chapman MJ, Humphries SE, et al. Familial hypercholesterolaemia is underdiagnosed and undertreated in the general population: guidance for clinicians to prevent coronary heart disease: consensus statement of the European
Atherosclerosis Society. Eur Heart J. 2013;34(45): 3478-90. https://doi.org/10.1093/eurheartj/eht273.

3. Sjouke B, Kusters DM, Kindt I, et al. Homozygous autosomal dominant hypercholesterolaemia in the Netherlands: prevalence, genotype-phenotype relationship, and clinical outcome. Eur Heart J. 2015;36(3):560-5. https://doi.org/10.1093/ eurheartj/ehu058.

4. Goldstein JL, Brown MS. Familial hypercholesterolemia: identification of a defect in the regulation of 3-hydroxy-3-methylglutaryl coenzyme A reductase activity associated with overproduction of cholesterol. Proc Natl Acad Sci U S A. 1973;70(10):2804-8.

5. Al-Nozha MM, Arafah MR, Al-Maatouq MA, et al. Hyperlipidemia in Saudi Arabia. Saudi Med J. 2008;29(2):282-7.

6. Basulaiman M, El Bcheraoui C, Tuffaha M, et al. Hypercholesterolemia and its associated risk factors-Kingdom of Saudi Arabia, 2013. Ann Epidemiol. 2014;24(11):801-8. https://doi.org/10. 1016/j.annepidem.2014.08.001.

7. Alasnag M, Awan Z, Al Ghamdi A, Al Modaimeigh $\mathrm{H}$, Al SM. Improvement initiative in LDL-C management in Saudi Arabia: a call to action. Int J Cardiol Heart Vasc. 2020;31:100667. https://doi. org/10.1016/j.ijcha.2020.100667.

8. Alsheikh-Ali AA, Omar MI, Raal FJ, et al. Cardiovascular risk factor burden in Africa and the Middle East: the Africa Middle East Cardiovascular Epidemiological (ACE) study. PLoS One. 2014;9(8): e102830. https://doi.org/10.1371/journal.pone. 0102830 .

9. Al-Rasadi K, Al-Zakwani I, Alsheikh-Ali AA, et al. Prevalence, management, and outcomes of familial hypercholesterolemia in patients with acute coronary syndromes in the Arabian Gulf. J Clin Lipidol. 2018;12(3):685-92.e2. https://doi.org/10.1016/j. jacl.2018.02.003.

10. Nanchen D, Gencer B, Auer R, et al. Prevalence and management of familial hypercholesterolaemia in patients with acute coronary syndromes. Eur Heart J. 2015;36(36):2438-45. https://doi.org/10.1093/ eurheartj/ehv289.

11. Al-Rasadi K, Alhabib KF, Al-Allaf F, et al. The Gulf familial hypercholesterolemia registry (Gulf $\mathrm{FH}$ ): design, rationale and preliminary results. Curr Vasc Pharmacol. 2020;18(1):57-64. https://doi.org/10. 2174/1570161116666181005125459.

12. Al-Ashwal A, Alnouri F, Sabbour H, et al. Identification and treatment of patients with homozygous familial hypercholesterolaemia: information and 
recommendations from a middle east advisory panel. Curr Vasc Pharmacol. 2015;13(6):759-70.

13. Bamimore MA, Zaid A, Banerjee A, et al. Familial hypercholesterolemia mutations in the Middle Eastern and North African region: a need for a national registry. J Clin Lipidol. 2015. https://doi. org/10.1016/j.jacl.2014.11.008.

14. Fareed M, Afzal M. Genetics of consanguinity and inbreeding in health and disease. Ann Hum Biol. 2017;44(2):99-107. 03014460.2016 .1265148 .

15. el-Hazmi MA, al-Swailem AR, Warsy AS, al-Swailem AM, Sulaimani R, al-Meshari AA. Consanguinity among the Saudi Arabian population. J Med Genetics. 1995;32(8):623-6. https://doi.org/10. 1136/jmg.32.8.623.

16. Warsy AS, Al-Jaser MH, Albdass A, Al-Daihan S, Alanazi M. Is consanguinity prevalence decreasing in Saudis?: a study in two generations. Afr Health Sci. 2014;14(2):314-21. https://doi.org/10.4314/ ahs.v14i2.5.

17. Al-Allaf FA, Alashwal A, Abduljaleel Z, et al. Identification of a recurrent frameshift mutation at the LDLR exon 14 (c.2027delG, p.(G676Afs*33)) causing familial hypercholesterolemia in Saudi Arab homozygous children. Genomics. 2016;107(1): 24-32. https://doi.org/10.1016/j.ygeno.2015.12. 001.

18. Al-Allaf FA, Athar M, Abduljaleel Z, et al. Identification of a novel nonsense variant c.1332dup, p. $\left(\mathrm{D} 445^{*}\right)$ in the LDLR gene that causes familial hypercholesterolemia. Hum Genome Var. 2014;1: 14021. https://doi.org/10.1038/hgv.2014.21.

19. Al-Allaf FA, Athar M, Abduljaleel Z, et al. Next generation sequencing to identify novel genetic variants causative of autosomal dominant familial hypercholesterolemia associated with increased risk of coronary heart disease. Gene. 2015;565(1):76-84. https://doi.org/10.1016/j.gene.2015.03.064.

20. Alallaf F, Nazar FAH, Alnefaie $M$, et al. The spectrum of familial hypercholesterolemia (FH) in Saudi Arabia: prime time for patient $\mathrm{FH}$ registry. Open Cardiovas Med J. 2017;11:66-75. https://doi.org/10. 2174/1874192401711010066.

21. Ned RM, Sijbrands EJ. Cascade screening for familial hypercholesterolemia (FH). PLoS Curr. 2011;3: RRN1238. https://doi.org/10.1371/currents. RRN1238.

22. Alharbi KK, Kashour TS, Al-Hussaini W, et al. Screening for genetic mutations in LDLR gene with familial hypercholesterolemia patients in the Saudi population. Acta Biochim Pol. 2015;62(3):559-62. https://doi.org/10.18388/abp.2015_1015.

23. Franke JG, Lansberg PJ. Dutch national screening and disease management program for familial hypercholesterolemia (FH) - a model for Saudi Arabia? J Saudi Heart Assoc. 2009;21(4):259-60. https://doi.org/10.1016/j.jsha.2009.10.013.

24. Batais MA, Almigbal TH, Bin Abdulhak AA, Altaradi $\mathrm{HB}$, AlHabib KF. Assessment of physicians' awareness and knowledge of familial hypercholesterolemia in Saudi Arabia: is there a gap? PLoS One. 2017;12(8):e0183494. journal.pone.0183494.

25. Arnous MM, Alghamdi AM, Ghoraba MA. Assessment of family physicians' awareness and knowledge of familial hypercholesterolemia in governmental hospitals in Riyadh, Saudi Arabia. J Family Med Prim Care. 2019;8(6):1981-6. https:// doi.org/10.4103/jfmpc.jfmpc_285_19.

26. Alzahrani SH, Bima A, Algethami MR, Awan Z. Assessment of medical intern's knowledge, awareness and practice of familial hypercholesterolemia at academic institutes in Jeddah, Saudi Arabia. Lipids Health Dis. 2020;19(1):101. https://doi.org/ 10.1186/s12944-020-01266-y.

27. Kastelein JJP, Reeskamp LF, Hovingh GK. Familial hypercholesterolemia: the most common monogenic disorder in humans. J Am Coll Cardiol. 2020;75(20):2567-9. https://doi.org/10.1016/j.jacc. 2020.03.058.

28. Mach F, Baigent C, Catapano AL, et al. 2019 ESC/ EAS guidelines for the management of dyslipidaemias: lipid modification to reduce cardiovascular risk. Eur Heart J. 2020;41(1):111-88. https://doi. org/10.1093/eurheartj/ehz455.

29. Gagne C, Gaudet D, Bruckert E, et al. Ezetimibe significantly reduces low-density lipoprotein cholesterol in homozygous familial hypercholesterolemia. J Am Coll Cardiol. 2002;39(s1):227. https://doi.org/10.1016/S0735-1097(02)81012-9.

30. Marais AD, Firth JC, Blom DJ. Homozygous familial hypercholesterolemia and its management. Sem Vasc Med. 2004;4(1):43-50. https://doi.org/10. 1055/s-2004-822985.

31. Raal FJ, Pilcher GJ, Panz VR, et al. Reduction in mortality in subjects with homozygous familial hypercholesterolemia associated with advances in lipid-lowering therapy. Circulation. 2011;124(20): 2202-7. CIRCULATIONAHA.111.042523.

32. Rader DJ, Cohen J, Hobbs HH. Monogenic hypercholesterolemia: new insights in pathogenesis and 
treatment. J Clin Invest. 2003;111(12):1795-803. https://doi.org/10.1172/JCI18925.

33. Al Sebayel M, Abaalkhail F, Al Abbad S, et al. Liver transplantation in the Kingdom of Saudi Arabia. Liver Transpl. 2017;23(10):1312-7. https://doi.org/ 10.1002/lt.24803.

34. Stefanutti C, Julius U, Watts GF, et al. Toward an international consensus-integrating lipoprotein apheresis and new lipid-lowering drugs. J Clin Lipidol. 2017;11(4):858-713. https://doi.org/10. 1016/j.jacl.2017.04.114.

35. Bruckert E, Saheb S, Bonté JR, Coudray-Omnès C. Daily life, experience and needs of persons suffering from homozygous familial hypercholesterolaemia: insights from a patient survey. Atheroscler Suppl. $2014 ; 15: 46-51$.

36. Horton JD, Cohen JC, Hobbs HH. PCSK9: a convertase that coordinates LDL catabolism. J Lipid Res. 2009;50(Suppl):S172-7. https://doi.org/10. 1194/jlr.R800091-JLR200.

37. Raal FJ, Honarpour N, Blom DJ, et al. Trial evaluating evolocumab, a PCSK9 antibody in patients with homozygous FH (TESLA): results of the randomised, double-blind placebo-controlled trial. European Atherosclerosis Society; Madrid, Spain; 2014. Abstract 1177.

38. Raal FJ, Honarpour N, Blom DJ, et al. Inhibition of PCSK9 with evolocumab in homozygous familial hypercholesterolaemia (TESLA Part B): a randomised, double-blind, placebo-controlled trial. Lancet. 2015;385(9965):341-50. https://doi.org/10. 1016/S0140-6736(14)61374-X.

39. Stein EA, Giugliano RP, Koren MJ, et al. Efficacy and safety of evolocumab (AMG 145), a fully human monoclonal antibody to PCSK9, in hyperlipidaemic patients on various background lipid therapies: pooled analysis of 1359 patients in four phase 2 trials. Eur Heart J. 2014;35(33):2249-59. https://doi. org/10.1093/eurheartj/ehu085.

40. Stein EA, Honarpour N, Wasserman SM, Xu F, Scott $\mathrm{R}$, Raal FJ. Effect of the proprotein convertase subtilisin/kexin 9 monoclonal antibody, AMG 145, in homozygous familial hypercholesterolemia. Circulation. 2013;128(19):2113-20. https://doi.org/10. 1161/CIRCULATIONAHA.113.004678.

41. Ogura M. PCSK9 inhibition in the management of familial hypercholesterolemia. J Cardiol. 2018;71(1):1-7. https://doi.org/10.1016/j.jjcc.2017. 07.002 .
42. Raal FJ, Hovingh GK, Blom D, et al. Long-term treatment with evolocumab added to conventional drug therapy, with or without apheresis, in patients with homozygous familial hypercholesterolaemia: an interim subset analysis of the open-label TAUSSIG study. Lancet Diabetes Endocrinol. 2017. https://doi.org/10.1016/S2213-8587(17)30044-X.

43. Cuchel M, Bloedon LT, Szapary PO, et al. Inhibition of microsomal triglyceride transfer protein in familial hypercholesterolemia. $\mathrm{N}$ Engl J Med. 2007;356(2):148-56. https://doi.org/10.1056/ NEJMoa061189.

44. Blom DJ, Averna MR, Meagher EA, et al. Long-term efficacy and safety of the microsomal triglyceride transfer protein inhibitor lomitapide in patients with homozygous familial hypercholesterolemia. Circulation. 2017;136(3):332-5. https://doi.org/10. 1161/CIRCULATIONAHA.117.028208.

45. Cuchel M, Meagher EA, du Toit TH, et al. Efficacy and safety of a microsomal triglyceride transfer protein inhibitor in patients with homozygous familial hypercholesterolaemia: a single-arm, openlabel, phase 3 study. Lancet. 2013;381(9860):40-6. https://doi.org/10.1016/S0140-6736(12)61731-0.

46. Roeters van Lennep J, Averna M, Alonso R. Treating homozygous familial hypercholesterolemia in a real-world setting: experiences with lomitapide. J Clin Lipidol. 2015;9(4):607-17. https://doi.org/10. 1016/j.jacl.2015.05.001.

47. Aegerion Pharmaceuticals Inc. Juxtapid prescribing information. 2013.

48. Amryt Pharmaceuticals DAC. Lojuxta summary of product characteristics. 2015.

49. Underberg J, Cannon C, Larrey D, Makris L, Phillips $\mathrm{H}$, Blom D. Long-term safety and efficacy of lomitapide in patients with homozygous familial hypercholesterolemia: five-year data from the lomitapide observational worldwide evaluation registry (LOWER). J Am Coll Cardiol. 2020;11(Suppl):1. https://doi.org/10.1016/S07351097(20)32619-X.

50. Larrey D, Underberg J, Cannon C, Makris L, Jurecka A, Blom D. Long-term liver safety of lomitapide in patients with homozygous familial hypercholesterolemia: three-year data from the lomitapide observational worldwide evaluation registry (LOWER). J Hepatol. 2018;68(Suppl. 1):S588. 